\title{
Effects of dietary live yeast supplementation on growth performance, diarrhoea severity, intestinal permeability and immunological parameters of weaned piglets challenged with enterotoxigenic Escherichia coli K88
}

\author{
Lianqiang Che ${ }^{1 *} \dagger$ Qin $\mathrm{Xu}^{1} \dagger$ Cheng $\mathrm{Wu}^{1}$, Yuheng Luo ${ }^{1 *}$, Xiaobo Huang ${ }^{2}$, Bo Zhang ${ }^{3}$, Eric Auclair ${ }^{3}$, \\ Tadele Kiros ${ }^{3}$, Zhengfeng Fang ${ }^{1}$, Yan Lin ${ }^{1}$, Shengyu Xu ${ }^{1}$, Bin Feng ${ }^{1}$, Jian $\mathrm{Li}^{1}$ and De Wu ${ }^{1}$ \\ ${ }^{1}$ Institute of Animal Nutrition, Sichuan Agricultural University, No. 211, Huimin Road, Wenjiang District, Chengdu, \\ Sichuan 611130, People's Republic of China \\ ${ }^{2}$ College of Veterinary Medicine, Sichuan Agricultural University, No. 211, Huimin Road, Wenjiang District, Chengdu, \\ Sichuan 611130, People's Republic of China \\ ${ }^{3}$ Phileo Lesaffre Animal Care, 59700 Marcq-en-Baroeul, France
}

(Submitted 25 April 2017 - Final revision received 25 September 2017 - Accepted 2 October 2017-First published online 23 November 2017)

\section{Abstract}

This study aimed to investigate the effects of dietary live yeast (LY) supplementation on growth, intestinal permeability and immunological parameters of piglets challenged with enterotoxigenic Escherichia coli K88 (ETEC). Piglets weaned at $21 \mathrm{~d}$ were allocated into three treatments with six pens and six piglets per pen, receiving the control diet (CON), diets supplemented with antibiotics plus zinc oxide (ANT-ZnO) and LY (Saccharomyces cerevisiae strain CNCM I-4407), respectively, for a period of 2 weeks. On day 8, thirty-six piglets were selected as control without ETEC (CON), CON-ETEC, ANT-ZnO-ETEC and LY-ETEC groups challenged with ETEC until day 10 for sample collections. Piglets fed ANT-ZnO diet had the highest average daily gain and average daily feed intake $(P<0.05)$ during the 1 st week, but ADG of piglets fed the ANT-ZnO diet was similar as piglets fed LY diet during the second week. Piglets with LY-ETEC or ANT-ZnO-ETEC had markedly lower diarrhoea score $(P<0.05)$ than piglets with CON-ETEC during the $24 \mathrm{~h}$ after ETEC challenge. Relative to piglets with CON, the counts of E. coli, urinary ratio of lactulose to mannitol, plasma IL- 6 concentration, mRNA abundances of innate immunity-related genes in ileum and mesenteric lymph node tissues were increased $(P<0.05)$, whereas the villous height of jejunum and relative protein expression of ileum claudin-1 were decreased $(P<0.05)$ in piglets with CON-ETEC; however, these parameters did not markedly change in piglets with LY-ETEC or ANT-ZnO-ETEC. In summary, dietary LY supplementation could alleviate the severity of diarrhoea in piglets with ETEC, which may be associated with the improved permeability, innate immunity and bacterial profile.

Key words: Antibiotics: Zinc oxide: Immunity: Microbiota: Inflammation

Post-weaning diarrhoea, induced by enterotoxigenic Escherichia coli (ETEC), is one of reasons causing poor growth performance and swine disease. The in-feed antibiotics have been widely used in weaning diets to prevent diarrhoea incidences and as growth promoters in piglets ${ }^{(1,2)}$. Since the pharmacological dose of $\mathrm{ZnO}$ at $3000 \mathrm{mg} / \mathrm{kg}$ was first reported to reduce diarrhoea and increase growth rates in weaned pigs ${ }^{(3)}$, moreover, many studies have confirmed this improvement on intestinal health and body weight (BW) gain in the first 2 weeks after weaning ${ }^{(4-7)}$. Accordingly, the combination of in-feed antibiotics and pharmacological dose of $\mathrm{ZnO}$ had been widely used in pig diet. However, the environmental pollution and antibiotics resistance of pathogen, resulting from in-feed antibiotics and $\mathrm{ZnO}^{(8,9)}$, promotes us to seek the alternative strategies.

Live yeast (LY) (Saccharomyces spp.) has been used as a preventive and therapeutic agent for intestinal diseases in humans and animals ${ }^{(10)}$. The Saccharomyces cerevisiae $\mathrm{CNCM}$ I-4407 strain has been found to have anti-inflammatory effect $^{(11-13)}$, increase antibody levels of sow milk and immunity of piglets $^{(14)}$ and reduce incidences of diarrhoea, as well as the mortality of piglets infected with ETEC ${ }^{(15,16)}$. To our knowledge, however, the effects of replacing both antibiotics and zinc oxide by LY on growth performance, diarrhoea severity and intestinal and immunological parameters have rarely been reported. In this study, we hypothesised that the inclusion of LY in the diet would

Abbreviations: ADG, average daily gain; ANT-ZnO, antibiotics plus zinc oxide; BW, body weight; CON, control diet; ETEC, enterotoxigenic Escherichia coli K88; LY, live yeast.

* Corresponding authors: L. Che, fax +86 28 86291256, email clianqiang@hotmail.com; Y. Luo, email 1746515510@qq.com

$\dagger$ Lianqiang Che and Qin Xu contributed equally to this article. 
maintain similar effects as the combination of antibiotics and zinc oxide on growth, diarrhoea, intestinal permeability and immunological function of piglets challenged with ETEC.

\section{Methods \\ Ethics approval}

All experimental protocols for the present study were approved by the Animal Care and Use Committee of Sichuan Agricultural University, and carried out in accordance with the National Research Council's Guide for the Care and Use of Laboratory Animals.

\section{Animals, housing and experimental design}

A total of 108 piglets (Duroc $\times$ (Landrace $\times$ Yorkshire)), weaned at 21 ( $\mathrm{SE} 2$ ) $\mathrm{d}$ of age, were moved to the piglet experimental house with a controlled temperature at $28-30^{\circ} \mathrm{C}$. The piglet experimental house contained eighteen pens $(1.5 \times 1.5 \mathrm{~m})$ with infrared lamps (250 W) hanged above the pens. Before weaning, no creep feed was supplied. The initial BW of piglets was 6.39 ( $\mathrm{SE} 0.05) \mathrm{kg}$ and randomly allocated into three dietary treatments with six pens and six piglets (three barrows and three gilts) per pen, receiving the control diet (CON), diet supplemented with antibiotic plus $\mathrm{ZnO}$ (ANT-ZnO, $20 \mathrm{mg} / \mathrm{kg}$ of Colistin $+75 \mathrm{mg} / \mathrm{kg}$ of Aureomycin $+2100 \mathrm{mg} / \mathrm{kg}$ of $\mathrm{ZnO})$ and diet supplemented with LY $S$. cerevisiae (strain CNCM I-4407, $10^{10}$ colony-forming units (CFU/g) Actisaf ${ }^{\circledR} ;$ Phileo Lesaffre Animal Care) at $1 \mathrm{~g}$ per $\mathrm{kg} \operatorname{diet}(\mathrm{LY})$, respectively. The ingredient composition and nutrient levels of CON diet are presented in Table 1; ANT-ZnO and LY diets were formulated at the expenses of maize grain. All piglets had free access to feed and water; the experimental period lasted for 2 weeks.

\section{Enterotoxigenic Escherichia coli K88 challenge}

On day 8, two male piglets in each pen in the CON group and one male piglet in each pen in the ANT-ZnO and LY groups were selected to be individually fed in metabolic cages $(1.2 \times 0.4 \times 0.5 \mathrm{~m})$, with environmentally controlled rooms (28$30^{\circ} \mathrm{C}$ ). The selected piglets were healthy with $\mathrm{BW}$ near the average BW of each pen. Piglets from the CON group received either $100 \mathrm{ml}$ of sterilised Luria broth as the unchallenged group (CON, $n$ 6) or Luria Broth containing $10^{9} \mathrm{CFU} / \mathrm{ml}$ ETEC (serotype O149:K91:K88ac; China Veterinary Culture Collection Center) as the challenge group (CON-ETEC, $n$ 6), whereas piglets from ANT-ZnO $(n 6)$ and LY $(n 6)$ groups also received ETEC as challenge groups named by ANT-ZnO-ETEC and LYETEC groups. During the challenge study, piglets from CON, ANT-ZnO or LY groups were fed CON, ANT-ZnO or LY diets, respectively. The ETEC-challenged and unchallenged piglets were housed in separate sanitary rooms to avoid crosscontamination between groups. The diarrhoea scores were recorded at 6, 12, 24 and $36 \mathrm{~h}$ after ETEC challenge (1, normal; 2, pasty; 3, semi-liquid; 4, watery) and considered diarrhoeic when scored for 3 and 4 .
Table 1. Ingredient composition and nutrient levels of CON diet (as fed basis, \%)

\begin{tabular}{|c|c|}
\hline Ingredients & $\%$ \\
\hline Maize grain, $8 \% \mathrm{CP}$ & $35 \cdot 80$ \\
\hline Broken rice, $10.4 \% \mathrm{CP}$ & $17 \cdot 00$ \\
\hline Soyabean oil & 2.00 \\
\hline Sucrose & $2 \cdot 00$ \\
\hline Glucose & $2 \cdot 00$ \\
\hline Expanded soya, $35.5 \% \mathrm{CP}$ & $6 \cdot 00$ \\
\hline Whey powder, $2 \%$ CP & $10 \cdot 00$ \\
\hline De-hulled soyabean meal, $46 \% \mathrm{CP}$ & $13 \cdot 00$ \\
\hline Fishmeal, $62.5 \%$ CP & 4.00 \\
\hline Plasma protein powder, $78 \% \mathrm{CP}$ & $2 \cdot 00$ \\
\hline Yeast extract,75.6\%CP & $2 \cdot 00$ \\
\hline L-Lys·HCL, $98 \%$ & 0.47 \\
\hline DL-Met, $98.5 \%$ & 0.28 \\
\hline L-Thr, $98 \%$ & 0.23 \\
\hline L-Trp, $98 \%$ & 0.10 \\
\hline Choline chloride, $50 \%$ & 0.16 \\
\hline $\mathrm{CaCO}_{3}$ & 1.00 \\
\hline $\mathrm{CaHPO}_{4}$ & 0.65 \\
\hline Salt & 0.40 \\
\hline Acidifier & 0.50 \\
\hline Mould inhibitor & $0 \cdot 10$ \\
\hline Antioxidant & 0.03 \\
\hline Mycotoxin absorbent & 0.05 \\
\hline Mineral mixture, $0.2 \%$ * & 0.20 \\
\hline Vitamin mixture, $0.03 \% \dagger$ & 0.03 \\
\hline Total & $100 \cdot 00$ \\
\hline Nutrient levels & \\
\hline Digestible energy (Mcal/kg) $\ddagger$ & 3.50 \\
\hline CP (\%) & $19 \cdot 41$ \\
\hline $\mathrm{Ca}(\%)$ & 0.88 \\
\hline Available P (\%) & 0.43 \\
\hline Digestable Lys (\%) & 1.42 \\
\hline Digestable Met (\%) & 0.53 \\
\hline Digestable Cys,\% & 0.31 \\
\hline Digestable SAA (\%) & 0.83 \\
\hline Digestable Thr (\%) & 0.91 \\
\hline Digestable Trp (\%) & 0.41 \\
\hline \multicolumn{2}{|c|}{ 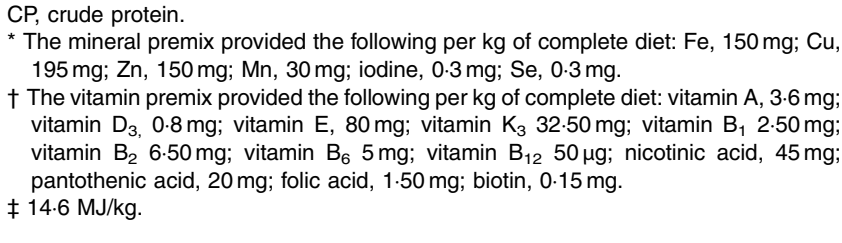 } \\
\hline
\end{tabular}

\section{Collection of blood and tissue samples}

At 08.00 hours after $2 \mathrm{~d}$ of ETEC challenge, blood samples were collected via the anterior vena cava puncture, and $5 \mathrm{ml}$ of blood sample was injected into sodium heparin anti-coagulative tubes. Blood samples with sodium heparin anticoagulation were centrifuged $\left(3000 \mathrm{~g}, 15 \mathrm{~min}, 4^{\circ} \mathrm{C}\right.$ ) to obtain plasma samples and stored at $-80^{\circ} \mathrm{C}$ for assays. Immediately after the collection of blood samples, piglets were euthanised with intramuscular injection of $15 \mathrm{mg} / \mathrm{kg} \mathrm{BW}$ of pentobarbital sodium and slaughtered. As the previous study ${ }^{(17,18)}$, the duodenal, jejunal and ileal tissue samples of about $2 \mathrm{~cm}$ in length were stored in $4 \%$ paraformaldehyde solution for histological analyses. Ileal segments $(10 \mathrm{~cm}$ in length) were opened longitudinally and the contents were flushed with ice-cold PBS. Mucosa was collected by scraping using a sterile glass microscope slide at $4^{\circ} \mathrm{C}$, rapidly frozen in liquid $\mathrm{N}_{2}$ and stored at $-80^{\circ} \mathrm{C}$ for the analysis of protein expression. Another ileum $(3 \mathrm{~cm}$ in length) and 
mesenteric lymph node (MLN) tissue samples were collected snap-frozen and stored at $-80^{\circ} \mathrm{C}$ for the analysis of mRNA expression. Aliquots ( $10 \mathrm{~g}$ ) of freshly collected digesta from the proximal colon were put into steril Eppendorf tubes and immediately stored at $-70^{\circ} \mathrm{C}$ for bacterial analyses ${ }^{(19)}$.

\section{Measurements}

Growth performance. Throughout the study, the feed supplied to piglets per pen was recorded daily. Individual piglet BW and feed disappearance per pen was measured weekly to calculate average daily gain (ADG), average daily feed intake (ADFI) and F:G (ADFI:ADG ratio) for weeks 1 and 2, respectively.

Immunological parameters. Plasma concentrations of IL-6, IL- $1 \beta$ and IgA were evaluated using the spectrophotometric method (Spectra Max M2; Molecular Devices), following the protocols of commercially available ELISA kits (Nanjing Jiancheng Bioengineering Institute). The minimal detection limit was $0.5 \mathrm{ng} / 1$ for IL- $1 \beta, 2 \mathrm{ng} / 1$ for IL- 6 and $10 \mu \mathrm{g} / \mathrm{ml}$ for IgA, respectively. In addition, the plasma concentrations of $\operatorname{IgG}$ and IgM were detected using the automatic biochemical analyzer (Model 7020; Hitachi), followed the protocols from the assay kits (Sichuan Maker Biotechnology Co. Ltd); the minimal detection limit was $0.8 \mathrm{~g} / \mathrm{l}$ for IgG and $30 \mathrm{mg} / \mathrm{l}$ for IgM, respectively. The intra-assay and inter-assay CV were $<5 \%$ for each assay.

Intestinal morphology. The duodenal, jejunal and ileal samples were embedded in paraffin. Each sample (duodenum, jejunum and ileum) was used to prepare five slides, and each slide had three sections ( 5 - $\mu$ m thickness), which were stained with haematoxylin-eosin for intestinal morphology measurement by twenty well-oriented villi and crypts in each section (Optimus software version 6.5; Media Cybergenetics), and villous height:crypt depth ratio (VCR) was calculated.

Intestinal permeability. For the test of intestinal permeability, at $4 \mathrm{~h}$ before euthanasia, the piglets were dosed intra-gastrically with $20 \mathrm{ml}$ of distilled water containing $500 \mathrm{mg}$ lactulose/ $\mathrm{kg} \mathrm{BW}$ (Sigma-Aldrich) and $50 \mathrm{mg}$ mannitol/kg BW (Sigma-Aldrich). Urinary concentrations of lactulose and mannitol $(10 \mathrm{ml})$, collected by cystocentesis at the time of euthanasia, were measured using an enzymatic spectrophotometric method (Spectra Max M2), following the protocols of commercial kits for lactulose (GMS19199.3; GENMED SCIENTIFICS INC.) and mannitol (GMS19049.4, GENMED SCIENTIFICS INC.) ${ }^{(20,21)}$. The urinary recovery ( $\%$ of administered dose) of lactulose or mannitol was calculated, and the ratio between the recovery percentages of lactulose and mannitol was considered as an index of intestinal permeability ${ }^{(22)}$.

Gene expressions. As the previous study by $\mathrm{Hu}$ et al. ${ }^{(18)}$, total RNA was extracted from the frozen ileum and MNL tissues using Trizol Reagent (Invitrogen) according to the manufacturer's instructions. The quality and purity of RNA samples were assessed by electrophoresis on 1.0\% agarose gel and nucleic acid analyzer (A260/A280, Beckman DU-800; Beckman Coulter, Inc.), respectively. Subsequently, the RNA was performed at $37^{\circ} \mathrm{C}$ for $15 \mathrm{~min}$, followed by RT inactivation at $85^{\circ} \mathrm{C}$ for $5 \mathrm{~s}$ using Prime Scripte $\mathrm{RT}^{\mathrm{TM}}$ reagent kit (Takara). Quantitative RT-PCR was performed

Table 2. Primer sequences of target and reference genes

\begin{tabular}{|c|c|c|c|}
\hline Genes & Primer sequence(5'-3') & Product (bp) & GenBank accession \\
\hline TLR-9 & $\begin{array}{l}\text { Forward: AATCCAGTCGGAGATGTTTGCT } \\
\text { Reverse: GACCGCCTGGGAGATGCT }\end{array}$ & 79 & AY859728 \\
\hline$T L R-4$ & $\begin{array}{l}\text { Forward: AGAAAATATGGCAGAGGTGAAAGC } \\
\text { Reverse: CTTCGTCCTGGCTGGAGTAGA }\end{array}$ & 64 & GQ304754 \\
\hline MyD88 & $\begin{array}{l}\text { Forward: GTGCCGTCGGATGGTAGTG } \\
\text { Reverse: TCTGGAAGTCACATTCCTTGCTT }\end{array}$ & 65 & NM001099923 \\
\hline TRAF-6 & $\begin{array}{l}\text { Forward: GCTGCATCTATGGCATTTTGAAG } \\
\text { Reverse: CCACAGATAACATTTGCCAAAGG }\end{array}$ & 70 & AJ606305.1 \\
\hline$N F-K B 1$ & $\begin{array}{l}\text { Forward: TGCTGGACCCAAGGACATG } \\
\text { Reverse: CTCCCTTCTGCAACAACACGTA }\end{array}$ & 60 & AK348766.1 \\
\hline SIGIRR & $\begin{array}{l}\text { Forward: ACCTGGGCTCCCGAAACTAC } \\
\text { Reverse: GTCATCTTCTGACACCAGGCAAT }\end{array}$ & 62 & AK239384.1 \\
\hline TOLLIP & $\begin{array}{l}\text { Forward: CCCGCGCTGGAATAAGG } \\
\text { Reverse: CATCAAAGATCTCCAGGTAGAAGGA }\end{array}$ & 74 & AK239879.1 \\
\hline IL-6 & $\begin{array}{l}\text { Forward: GATGCTTCCAATCTGGGTTCA } \\
\text { Reverse: CACAAGACCGGTGGTGATTCT }\end{array}$ & 62 & M80258.1 \\
\hline$I L-1 \beta$ & $\begin{array}{l}\text { Forward: TCTGCCCTGTACCCCAACTG } \\
\text { Reverse: CCAGGAAGACGGGCTTTTG }\end{array}$ & 64 & NM214055.1 \\
\hline Claudin-1 & $\begin{array}{l}\text { Forward: TCTTAGTTGCCACAGCATGG } \\
\text { Reverse: CCAGTGAAGAGAGCCTGACC }\end{array}$ & 106 & NM001244539 \\
\hline Occludin & $\begin{array}{l}\text { Forward: TTCATTGCTGCATTGGTGAT } \\
\text { Reverse: ACCATCACACCCAGGATAGC }\end{array}$ & 113 & NM001163647 \\
\hline$Z O-1$ & $\begin{array}{l}\text { Forward: CCGCCTCCTGAGTTTGATAG } \\
\text { Reverse: CAGCTTTAGGCACTGTGCTG }\end{array}$ & 97 & AJ318101 \\
\hline$\beta$-Actin & $\begin{array}{l}\text { Forward: GGCGCCCAGCACGAT } \\
\text { Reverse: CCGATCCACACGGAGTACTTG }\end{array}$ & 66 & DQ845171.1 \\
\hline
\end{tabular}

TLR, Toll-like receptor; MyD88, myeloid differentiation factor 88; TRAF-6, TNF receptor-associated factor 6; SIGIRR, single Ig IL-1-related receptor; TOLLIP, Toll-interacting protein; IL, IL; ZO-1, Zonula occludens protein-1. 
on a ABI-7900HT instrument (Applied Biosystems). Oligonucleotide primers were used to detect the expressions of the target genes and the reference gene ( $\beta$-actin) using the SYBR green system (Takara). The primer sequences are listed in Table 2 . The reaction mixture $(10 \mu \mathrm{l})$ contained $5 \mu \mathrm{l}$ of fresh SYBR ${ }^{\circledR}$ Premix Ex TaqII (Tli RNase H Plus) and $0 \cdot 2 \mu \mathrm{L}$ of ROX Reference Dye II (50x), $0 \cdot 8 \mu \mathrm{l}$ of the primers, $1 \mu \mathrm{l}$ of $\mathrm{RT}$ products and $3 \mu \mathrm{l}$ of diethylpyrocarbonate-treated water. The following PCR protocol was used: one cycle at $95^{\circ} \mathrm{C}$ for $30 \mathrm{~s}$, forty cycles at $95^{\circ} \mathrm{C}$ for $5 \mathrm{~s}$ and $60^{\circ} \mathrm{C}$ for $31 \mathrm{~s}$ and one cycle at $95^{\circ} \mathrm{C}$ for $15 \mathrm{~s}, 60^{\circ} \mathrm{C}$ for $1 \mathrm{~min}$ and $95^{\circ} \mathrm{C}$ for $15 \mathrm{~s}$. The standard curve of each gene was run in duplicate and three times for obtaining reliable amplification efficiency values. The correlation coefficients $(r)$ of all the standard curves were $>0.99$, and the amplification efficiency values were between 90 and $110 \%$. The $\beta$-actin transcript was used to standardise the mRNA expression of all genes. The relative quantification of gene expression among the treatment groups was analysed by the $2^{-\Delta \Delta C_{t}} \operatorname{method}^{(23)}$.

Western blot analysis for protein expressions. Western blot analysis was performed as previously described ${ }^{(24)}$; the frozen ileal mucosa was homogenised with cell lysis buffer for extracting total protein according to the method described for the cell lysis buffer in the Western and IP kit (Beyotime), and the protein concentration was determined using the Bicinchoninic Acid Protein Assay Kit (Pierce). Equal amounts of protein lysates $(100 \mu \mathrm{g})$ were separated on $12 \%$ SDS-PAGE and then transferred to apolyvinylidene fluoride membranes (Bio-Rad Laboratories), which were blocked in TBS-T buffer ( $50 \mathrm{~mm}$ TRIS-HCl, $150 \mathrm{~mm}$ $\mathrm{NaCl}, 0.1 \%$ Tween, $\mathrm{pH}$ 7.6) supplemented with 5\% bovine serum albumin (Sigma-Aldrich) at room temperature for $1.5 \mathrm{~h}$, followed by overnight incubation at $4^{\circ} \mathrm{C}$ with diluted antibodies against claudin-1 (1:250; Invitrogen), occludin (1:1000; Invitrogen) and $\beta$-actin (1:500; Santa Cruz). After $1 \mathrm{~h}$ of incubation with horseradish peroxidase-linked secondary antibody antimouse IgG (1:2000; Cell Signaling) at room temperature, chemiluminescence detection was performed using the ECL Plus TM Western Blotting Detection System (Amersham), according to the manufacturer's instructions. The relative expression of target protein was normalised using $\beta$-actin as the internal protein, and then the normalised values were used for comparison of the expression of target proteins across groups.
Bacterial counts in colonic contents. The frozen colonic contents were thawed for $10 \mathrm{~min}$. Samples were immediately weighed and serially diluted up to $10^{7}$ in sterile physiological saline. Dilutions were subsequently plated on duplicate selective agar media for enumeration of bacteria, including E. coli, Lactobacillus spp. and Bifidobacterium spp. The appropriate selective agar media, incubation conditions and period and colony identification were in accordance with those described by Giannenas et $a l^{(25)}$. In brief, diluted samples were plated on Man-Rogosa-Sharpe agar and Eosin Methylene Blue agar (Microbiology Laboratories) following anaerobic or aerobic incubation at $37^{\circ} \mathrm{C}$ for $24 \mathrm{~h}$ to count Lactobacillus spp. and $E$. coli, respectively, and plated on Reinforced Clostridial Agar (Microbiology Laboratories) following anaerobic incubation at $37^{\circ} \mathrm{C}$ for $48 \mathrm{~h}$ to count Bifidobacterium spp. Anaerobic incubation was achieved under anaerobic atmosphere $\left(80 \% \mathrm{~N}_{2}, 15 \%\right.$ $\mathrm{CO}_{2}$ and $5 \% \mathrm{H}_{2}$ ) without agitation. Results were expressed as base-10 logarithm CFU/g (wet mass) of colonic content (CFU/g).

\section{Statistical analysis}

The performance data were calculated separately for weeks 1 or 2, and the pen was recognised as a statistical unit for ADG, ADFI and F:G. The selected piglet in each pen was taken as an experimental unit for the parameters related to the intestinal and immunological function in the challenge study. Before the analyses, values of bacterial counts in colonic contents were transformed to $\log _{10}$ values. Data were analysed using the general linear models (GLM) procedure of SPSS 20.0 (SPSS Inc.). The change of diarrhoea scores of weaned piglets following an ETEC challenge was analysed by an unequally spaced repeated-measures and multivariate ANOVA process of the GLM in SPSS. Multi-comparison was conducted by Duncan's multiple-range test. The difference was considered to be significant at $P<0 \cdot 05$.

\section{Results}

Performance

During the 1st week, piglets fed LY diet had lower $(P<0.05)$ ADG and ADFI than piglets fed ANT-ZnO diet (Table 3).

Table 3. Growth performance of weaned piglets fed diets supplemented with antibiotics plus zinc oxide (ANT-ZnO) or live yeast (LY) (Mean values with their standard errors)

\begin{tabular}{|c|c|c|c|c|c|}
\hline & $\mathrm{CON}$ & ANT-ZnO & LY & SEM & $P$ \\
\hline Initial BW (kg) & $6 \cdot 35$ & $6 \cdot 38$ & $6 \cdot 37$ & 0.06 & 0.824 \\
\hline Final BW $(\mathrm{kg})$ & $9 \cdot 80^{\mathrm{b}}$ & $10 \cdot 54^{a}$ & $10 \cdot 12^{b}$ & 0.22 & 0.003 \\
\hline \multicolumn{6}{|l|}{ 1st week } \\
\hline$A D G(g)$ & $190^{\mathrm{b}}$ & $228^{a}$ & $192^{\mathrm{b}}$ & 15 & 0.013 \\
\hline ADFI (g) & $204^{\mathrm{b}}$ & $237^{a}$ & $210^{b}$ & 15 & 0.043 \\
\hline$F: G$ & 1.07 & 1.04 & $1 \cdot 10$ & 0.07 & 0.584 \\
\hline \multicolumn{6}{|l|}{ 2nd week } \\
\hline ADG (g) & $306^{\mathrm{b}}$ & $366^{a}$ & $344^{a, b}$ & 27 & 0.044 \\
\hline ADFI (g) & 418 & 495 & 471 & 55 & 0.251 \\
\hline$F: G$ & 1.36 & 1.35 & 1.37 & 0.01 & 0.970 \\
\hline
\end{tabular}

$B W$, body weight; $A D G$, average daily gain; $A D F I$, average daily feed intake; $F: G$, feed:gain ratio.

${ }^{a, b}$ Mean values within a row with unlike superscript letters were significantly different $(P<0.05)$. 


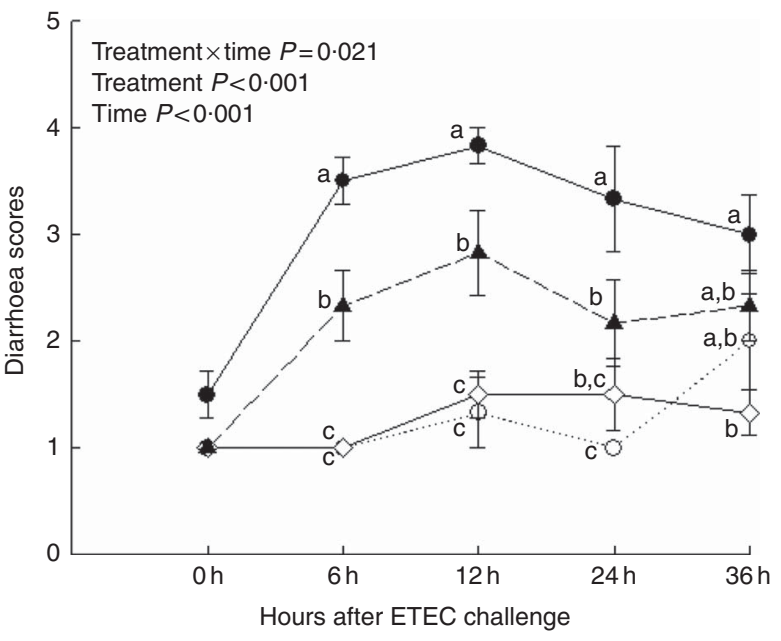

Fig. 1. Diarrhoea scores of weaned piglets fed diets supplemented with antibiotics plus zinc oxide (ANT-ZnO) or live yeast (LY) following an enterotoxigenic Escherichia coli K88 (ETEC) challenge. ... o ..., Control diet $(\mathrm{CON}) ; \multimap$, CON-ETEC; $\multimap$, ANT-ZnO-ETEC; $\multimap$, LY-ETEC. Values are means, with their standard errors represented by vertical bars. a,b,c Mean values with unlike letters were significantly different $(P<0.05)$.

During the 2nd week, however, piglets fed LY diet had similar ADG as piglets fed ANT-ZnO diet.

\section{Diarrhoea score and morphology}

Piglets with CON-ETEC had the higher diarrhoea scores $(P<0.05)$ than piglets with CON or ANT-ZnO-ETEC during the $24-h$ post challenge. However, the diarrhoea score in piglets with LY-ETEC had similar value as piglets with ANT-ZnOETEC at $24 \mathrm{~h}$ after ETEC challenge (Fig. 1). In addition, piglets with CON-ETEC had lower villous height in both jejunum and ileum $(P<0.05)$ than that of piglets with $\mathrm{CON}$, but piglets with LY-ETEC or ANT-ZnO-ETEC had similar villous height in jejunum as piglets with CON or CON-ETEC. Although piglets with ANT-ZnO-ETEC had higher villous height in the ileum $(P<0.05)$ than piglets with CON-ETEC, the villous height in the ileum did not markedly differ between piglets with LY-ETEC and ANT-ZnO-ETEC (Fig. 2(A)). There were no significant differences in the crypt depth (Fig. 2(B)) and ratio of VCR (Fig. 2(C)) across all treatments.

\section{Intestinal permeability and claudin-1 abundance}

The LR and LR:MR ratio were increased $(P<0.05)$ in the urine of piglets with CON-ETEC compared with piglets with CON; however, piglets with LY-ETEC or ANT-ZnO-ETEC had similar values on LR and LR:MR ratio as piglets with CON (Fig. 3). Relative to piglets with CON, the expression of intestinal tight junction protein claudin-1 was markedly lower $(P<0.05)$ in the ileum of piglets with CON-ETEC, whereas piglets with LY-ETEC or ANT-ZnO-ETEC maintained similar expression of claudin-1 as piglets with CON (Fig. 4(A)). There was no significant difference in the protein expression of occludin (Fig. 4(B)) and the gene expression of zonula occludens protein-1, occludin and claudin-1 (Fig. 4(C)) across all treatments.

\section{Bacterial counts in colonic contents}

The E. coli counts were increased $(P<0.05)$ in the colonic contents of piglets with CON-ETEC compared with piglets with CON, whereas the counts of both E. coli and Lactobacillius were markedly decreased in piglets with ANT-ZnO-ETEC. However, the counts of Lactobacillus were markedly higher $(P<0.05)$ in piglets with LY-ETEC than piglets with CON-ETEC or ANT-ZnO-ETEC (Fig. 5).

\section{Immunological and inflammatory responses}

ETEC challenge markedly decreased the plasma concentration of IgA than that of piglets without ETEC challenge. Moreover, piglets with CON-ETEC had markedly higher concentration of plasma IL-6 $(P<0.05)$ than that of piglets with CON; however, piglets with LY-ETEC or ANT-ZnO-ETEC had similar concentration of plasma IL-6 as that of piglets with CON (Table 4).

\section{Innate-immunity-related gene expressions}

The mRNA expressions of genes in the ileum (myeloid differentiation factor $88(M y D 88)$ and $I L-\sigma)$ and MLN $(N F-\kappa B$ and $I L-1 \beta)$ were up-regulated $(P<0.05)$ in piglets with CON-ETEC compared with piglets with CON, but these genes did not markedly differ between piglets with LY-ETEC and ANT-ZnO-ETEC. In addition, the mRNA expression of SIGIRR in both ileum and MLN were markedly up-regulated in piglets with ANT-ZnO-ETEC relative to piglets with CON or CON-ETEC (Fig. 6).

\section{Discussion}

Antibiotics or/and zinc oxide had been used in starter diet to prevent diarrhoea and stimulate the growth rate of weaning piglets $^{(7,26,27)}$. As a positive control, in this study, the combination of antibiotics and zinc oxide in the diet had improved ADG and final BW of piglets; however, the inclusion of LY in diet could maintain similar ADG as piglets fed the ANT-ZnO diet during the 2 nd week post weaning.

Compared with piglets with CON, during the $24 \mathrm{~h}$ after ETEC challenge, piglets with CON-ETEC exhibited diarrhoea with semi-liquid or watery faeces (scored at 3-4), however, which was normalised in piglets with ANT-ZnO-ETEC. Although piglets with LY-ETEC had diarrhoea with pasty or semi-liquid faeces (scored at 2-3) during the $12 \mathrm{~h}$, these piglets had similar diarrhoea score as piglets with ANT-ZnO-ETEC at $24 \mathrm{~h}$ after ETEC challenge, indicating the decreasing effect of LY on diarrhoea severity and duration in piglets with ETEC. Consistently, the recent studies showed that both severity and duration of diarrhoea in piglets could be reduced by feeding $L Y^{(15,16)}$. In addition, there was decreased villous height in the jejunum of piglets with CON-ETEC, however, which did not occur in piglets with LY-ETEC or ANT-ZnO-ETEC, suggesting the preventive role of LY or ANT-ZnO on the intestinal integrity of piglets. The previous studies have shown that diarrhoea and poor intestinal integrity are often associated with the activation of innate immunity and inflammatory process, in which the TLR4-Myd88-NF- $\mathrm{KB}$ signal pathway is involved ${ }^{(28-30)}$. In this 
(A)

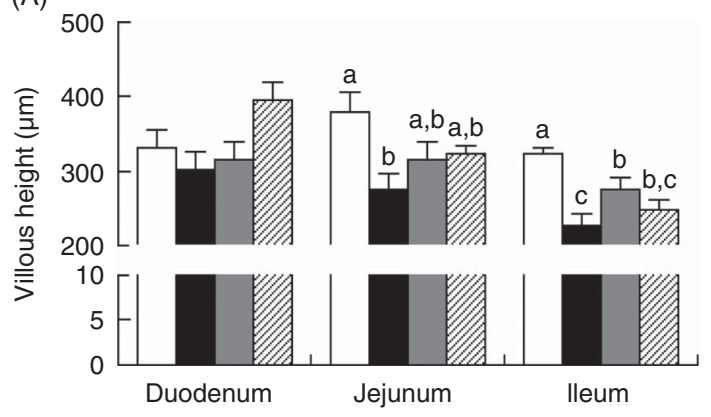

(B)

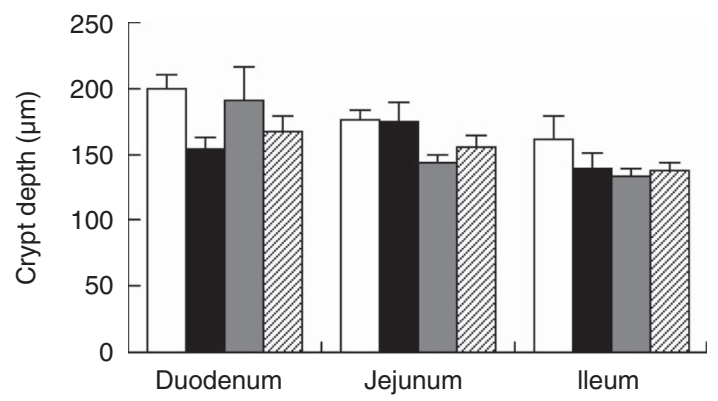

(C)

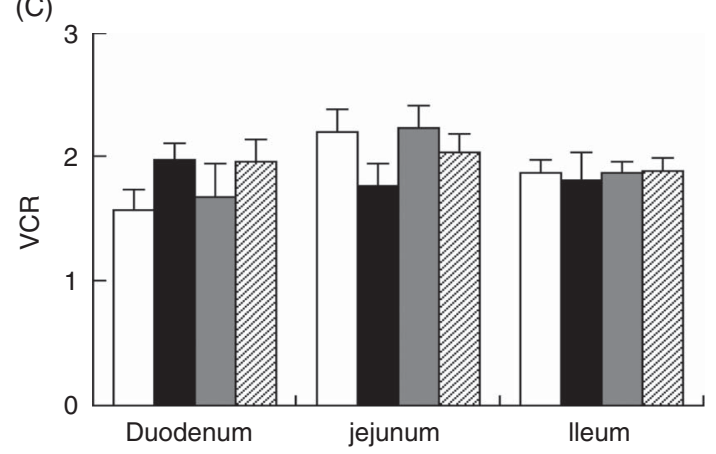

Fig. 2. Small-intestinal (A) villous height, (B) crypt depth and (C) the ratio of villous height:crypt depth (VCR) of weaned piglets fed diets supplemented with antibiotics plus zinc oxide (ANT-ZnO) or live yeast (LY) following an enterotoxigenic Escherichia coli K88 (ETEC) challenge. Values are means, with their standard errors represented by vertical bars. $\square$, Control diet (CON); $\square$, CON-ETEC; $\square$, ANT-ZnO-ETEC; $\square$, LY-ETEC. ${ }^{\text {a,b,c }}$ Mean values with unlike letters were significantly different $(P<0.05)$.

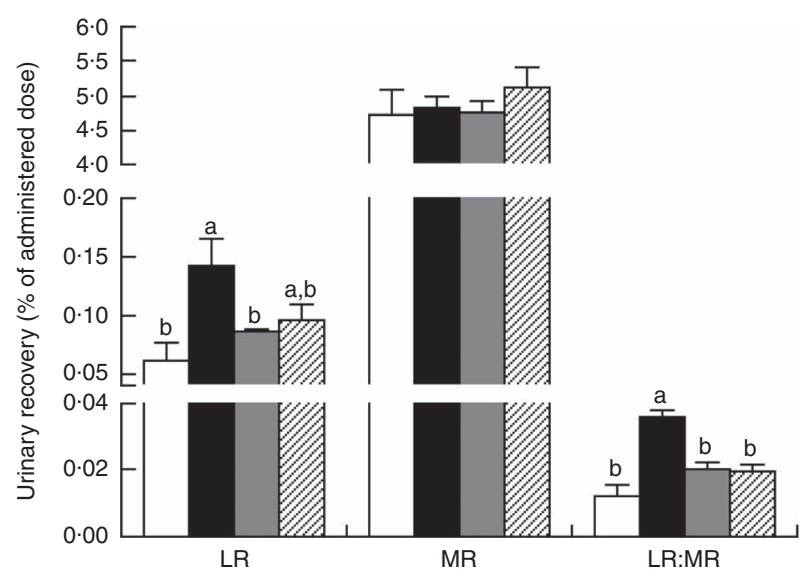

Fig. 3. Urinary recovery (\% of administered dose) of lactulose (LR) and mannitol (MR) and lactulose:mannitol ratios (LR:MR) of weaned piglets fed diets supplemented with antibiotics plus zinc oxide (ANT-ZnO) or live yeast (LY) following an enterotoxigenic Escherichia coli K88 (ETEC) challenge. Values are means, with their standard errors represented by vertical bars. $\square$, Control diet (CON); $\square$, CON-ETEC; $\square$, ANT-ZnO-ETEC; $\square$, LY-ETEC. ${ }^{a, b}$ Mean values with unlike letters were significantly different $(P<0.05)$.

study, we found that the innate-immunity-related genes that were highly expressed in the ileum tissues of piglets with CONETEC were down-regulated in the piglets with LY-ETEC or ANT-ZnO-ETEC, suggesting that the excessive innate immune response of piglets with ETEC may be alleviated by feeding LY or ANT-ZnO diet. Moreover, the inflammatory response of piglets under ETEC challenge may be alleviated by LY or
ANT-ZnO, as indicated by the lower concentration of plasma IL-6 in piglets with LY-ETEC or ANT-ZnO-ETEC. Similarly, a recent study also showed that dietary supplementation of Lactobacillus acidophilus GG, as a probiotic strain, could alleviate the inflammatory response of piglets to ETEC by modulating NF- $\mathrm{BB}$ and MAPK signalling pathways ${ }^{(31)}$. In this study, however, we did not observe the improvement of either LY or ANT-ZnO supplementation on the humoral immunity, as indicated by the decreasing concentration of plasma IgA in piglets with ETEC challenge; this result is inconsistent with the previous study by Trevisi et $a l .{ }^{(32)}$, who reported that ETEC challenge could not markedly alter the concentration of total blood IgA in piglets with Lactobacillus rhamnosus GG. The differential immune response of piglets to ETEC challenge may be related to the type of probiotics, ETEC strains or the challenge period. Furthermore, the inhibition of ANT-ZnO on innate immune and inflammatory response may be ascribed to their antibacterial activity ${ }^{(33,34)}$ and decreasing adhesion of bacteria ${ }^{(35,36)}$, as evidenced by the decreasing counts of E. coli and Lactobacillius in piglets with ANT-ZnO-ETEC, relative to piglets with CON-ETEC. In addition, the modulating effect of LY on inflammation or innate immunity had been attributed to the secreted molecules ${ }^{(11,12)}$ or probiotic effects, as indicated by the increased counts of Lactobacillius in piglets with LY-ETEC relative to piglets with CON-ETEC or ANT-ZnO-ETEC. More recent data suggest that the direct binding effect occurred between LY probiotics and pathogenic bacteria such as E. coli, Salmonella and Listeria ${ }^{(37)}$, which result in the competitive exclusion of exogenous pathogens from the intestinal lumen. In addition, lactic acid fermentation in S. cerevisiae lowered the gut $\mathrm{pH}$, which may inhibit the proliferation of $E$. $\operatorname{col}^{(38)}$. 
(A)

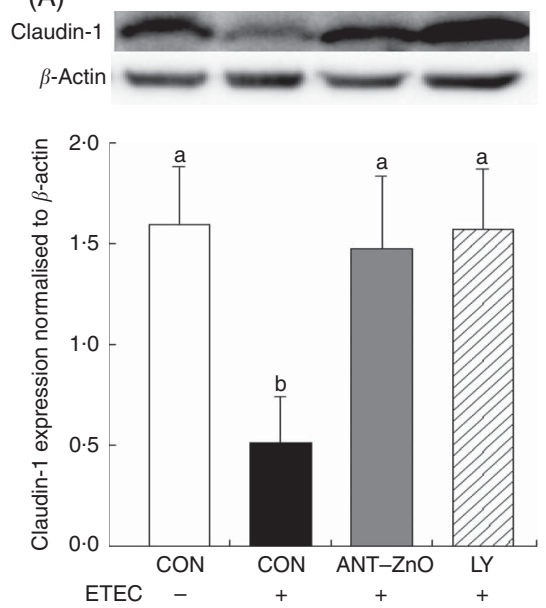

(B)
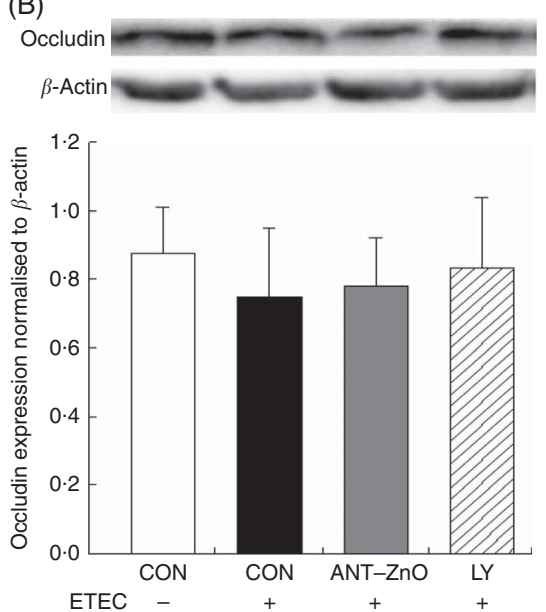

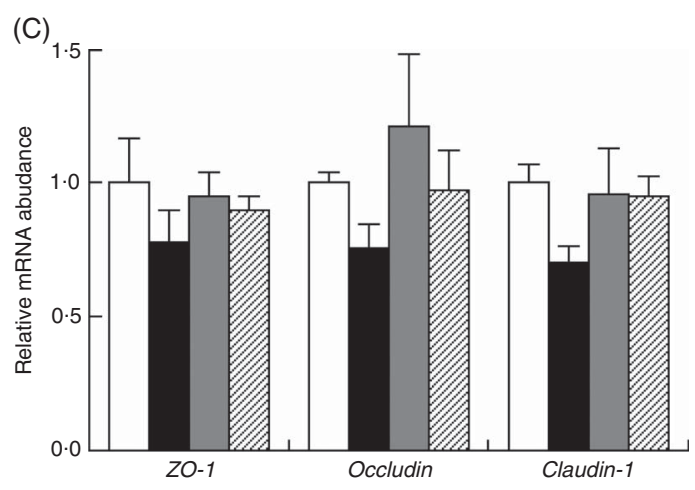

Fig. 4. Relative protein expressions of (A) claudin-1 and (B) occludin in ileum mucosa of weaned piglets fed diets supplemented with antibiotics plus zinc oxide (ANT$\mathrm{ZnO}$ ) or live yeast (LY) following an enterotoxigenic Escherichia coli K88 (ETEC) challenge. (C) Relative mRNA abundance of zonula occludens protein-1 (ZO-1), occludin and claudin-1 in ileum of weaned piglets fed diets supplemented with ANT-ZnO or LY following an ETEC challenge. Values are means, with their standard errors represented by vertical bars. $\square$, Control diet (CON); $\square$, CON-ETEC; $\square$, ANT-ZnO-ETEC; $\square$, LY-ETEC. ${ }^{\text {a,b }}$ Mean values with unlike letters were significantly different $(P<0.05)$.

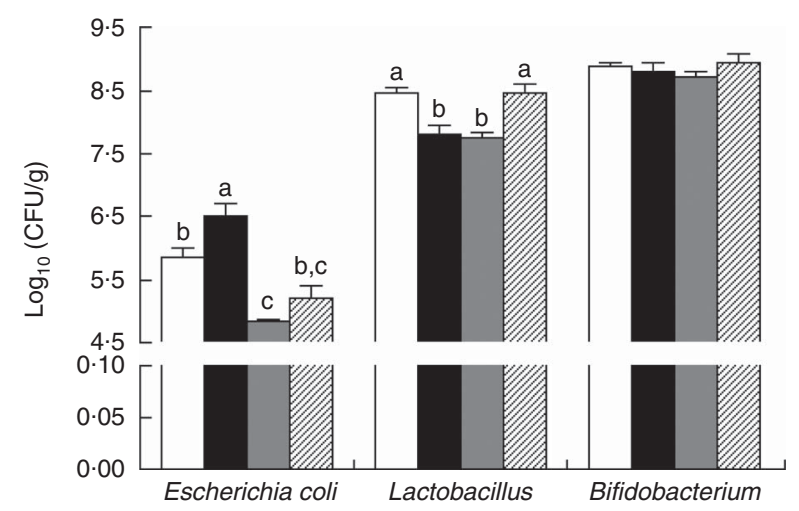

Fig. 5. The bacterial count in the colonic digesta of weaned piglets fed diets with antibiotics plus zinc oxide (ANT-ZnO) or live yeast (LY) following an enterotoxigenic Escherichia coli K88 (ETEC) challenge. Values are means, with their standard errors represented by vertical bars. CFU, colony-forming units; $\square$, control diet (CON); $\mathbf{a}$, CON-ETEC; $\square$, ANT-ZnO-ETEC; $\square, L Y-E T E C$. ${ }^{a, b, c}$ Mean values with unlike letters were significantly different $(P<0.05)$.

The intestinal bacteria has been shown to target various intracellular process including the expression and distribution of tight junction proteins, thereby modulating the intestinal permeability $^{(39)}$ and gastrointestinal diseases ${ }^{(40,41)}$. In this study, the intestinal permeability was increased in piglets with ETEC challenge, as indicated by the higher recovery of urine lactulose and ratio of lactulose to mannitol in piglets with CON-ETEC; however, these values did not markedly alter in piglets with LY-ETEC or ANT-ZnO-ETEC, suggesting the improvement of LY or ANT-ZnO on the intestinal permeability. Supportively, the higher expression of tight junction protein claudin-1 was observed in piglets with LY-ETEC or ANT-ZnO-ETEC relative to CON-ETEC. Similarly, the previous studies also showed that the supplementation of LY could improve the barrier function, as indicated by the increased expression of tight junction protein, thickness of mucosal layer and number of mucosal macrophages ${ }^{(42,43)}$.

\section{Conclusion}

The observations in the current study indicate that dietary LY supplementation could alleviate the severity of diarrhoea of piglets with ETEC, which may be associated with the improved intestinal permeability and immunity, as well as bacterial profile. 
Table 4. Immunoglobulin and inflammatory responses of weaned piglets fed diets supplemented with antibiotics plus zinc oxide (ANT$\mathrm{ZnO}$ ) or live yeast (LY) following an enterotoxigenic Escherichia coli K88 (ETEC) challenge (Mean values with their standard errors)

\begin{tabular}{lcccccc}
\hline & CON & CON-ETEC & ANT-ZnO-ETEC & LY-ETEC & SEM & $P$ \\
\hline $\operatorname{lgG}(\mathrm{g} / \mathrm{l})$ & 2.69 & 2.91 & 2.56 & 2.79 & 0.37 & 0.640 \\
$\operatorname{lgM}(\mathrm{g} / \mathrm{l})$ & 0.34 & 0.31 & 0.28 & 0.34 & 0.08 & 0.591 \\
$\operatorname{lgA}(\mathrm{g} / \mathrm{l})$ & $0.53^{\mathrm{a}}$ & $0.37^{\mathrm{b}}$ & $0.38^{\mathrm{b}}$ & $0.30^{\mathrm{b}}$ & 0.07 & 0.004 \\
$\mathrm{IL}-1 \beta(\mathrm{ng} / \mathrm{l})$ & 13.17 & 13.56 & 9.27 & 12.73 & 2.69 & 0.124 \\
$\mathrm{IL}-6(\mathrm{ng} / \mathrm{l})$ & $49.60^{\mathrm{b}}$ & $73.36^{\mathrm{a}}$ & $49.08^{\mathrm{b}}$ & $52.96^{\mathrm{a}, \mathrm{b}}$ & 1.44 & 0.044 \\
\hline
\end{tabular}

CON, control diet.

a,b Mean values within a row with unlike superscript letters were significantly different $(P<0.05)$.

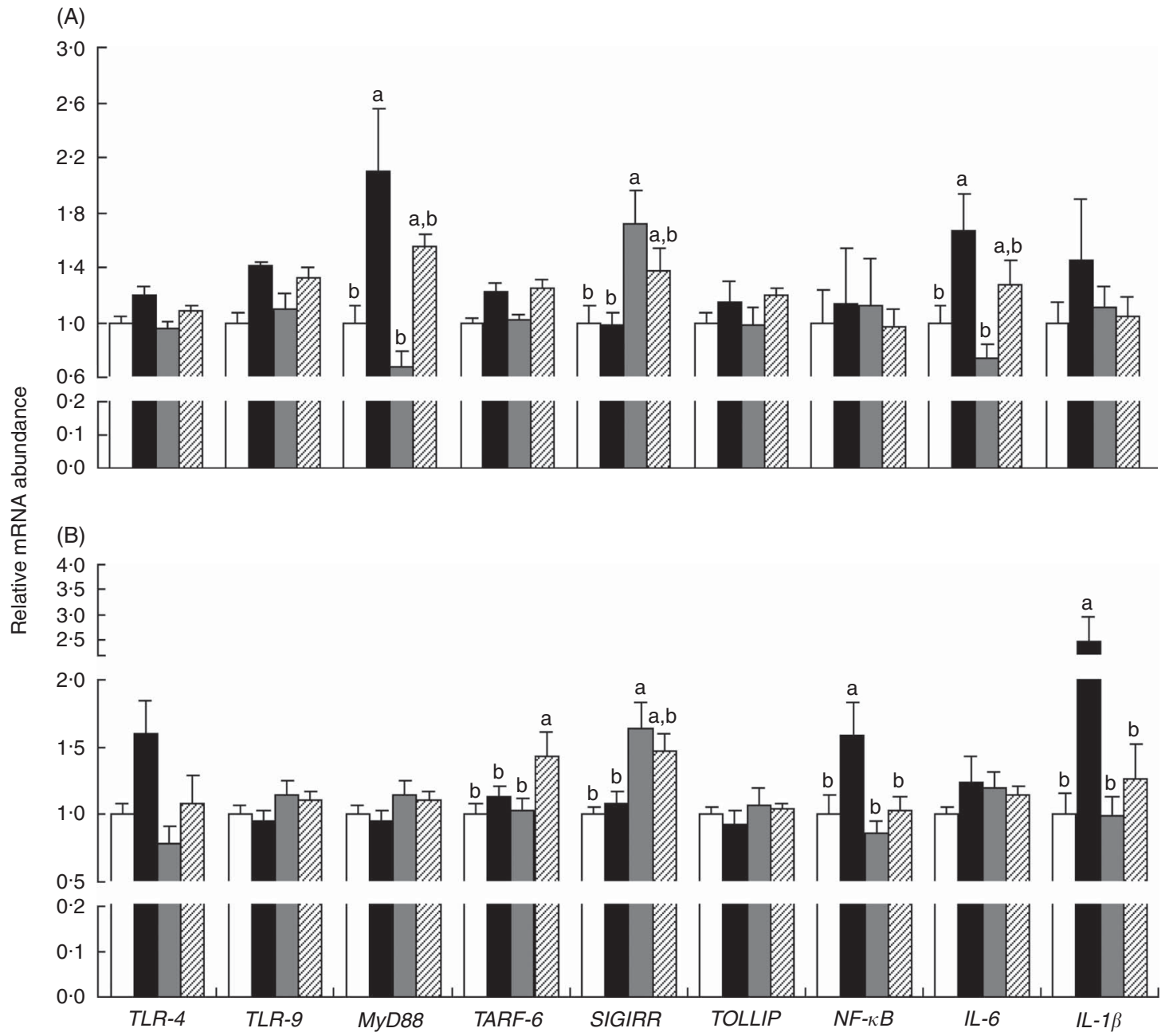

Fig. 6. Relative mRNA abundance in the ileum (A) and mesenteric lymphoid node (MLN, B) of weaned piglets fed diets supplemented with antibiotics plus zinc oxide (ANT-ZnO) or live yeast (LY) following an enterotoxigenic Escherichia coli K88 (ETEC) challenge. Values are means, with their standard errors represented by vertical

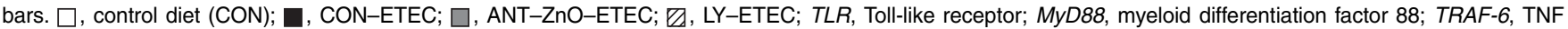
receptor-associated factor 6; SIGIRR, single Ig IL-1-related receptor; TOLLIP, Toll-interacting protein. ${ }^{a, b}$ Mean values with unlike letters were significantly different $(P<0.05)$.

\section{Acknowledgements}

We acknowledge Romain D'Incà, Liang Hu, Xie Peng, Yan Liu, Ru Wang, Linlin Qin, Yang Liu and Qiang Zhou for their suggestions about study design and technical assistance.

This project was funded by Phileo Lesaffre Animal Care, France (B. Z., E. A., grant no. C2729-01); the National Key Research and Development Program of China (L. C., Q. X., C. W.,
Y. L., grant no. 2016YFD0501204); Sichuan provincial project on S\&T application and demonstration (X. H., grant no. 2016CC0070); and the project on commercialisation of research findings under funding of the government of Sichuan province (Z. F., Y. L., S. X., B. F., J. L., D. W., grant no. 16ZHSF0385). The Phileo Lesaffre Animal Care (France) donated the live yeast Saccharomyces cerevisiae ( strain CNCM I-4407, Actisaf $^{\circledR}$ ) for this study and partly contributed to the study design. 
The authors' contributions are as follows: L. C., Q. X., B. Z. and $\mathrm{E}$. A. contributed to formulate the research questions and study design; Q. X., C. W., Y. L., Z. F., Y. L. and S. X carried out the study; X. H., B. F. and J. L. contributed to the sample analysis; L. C., Q. X. and D. W. contributed to the data analysis; and L. C., Q. X., C. W. and D. W. contributed to the data interpretation.

The authors declare that there are no conflicts of interest.

\section{References}

1. Pluske JR, Pethick DW, Hopwood DE, et al. (2002) Nutritional influences on some major enteric bacterial diseases of pig. Nutr Res Rev 15, 333-371.

2. Lange CFMD, Pluske J, Gong J, et al. (2010) Strategic use of feed ingredients and feed additives to stimulate gut health and development in young pigs. Livest Sci 134, 124-134.

3. Poulsen HD (1989) Zinc Oxide for Pigs During Weaning, Meddelelse no. 746. Foulum, Denmark: Statens Husdyrbrugsforsoeg.

4. Heo JM, Kim JC, Hansen CF, et al. (2010) Effects of dietary protein level and zinc oxide supplementation on the incidence of post-weaning diarrhoea in weaner pigs challenged with an enterotoxigenic strain of Escherichia coli. Livest Sci 133, 210-213.

5. McCully G A HGM \& Link J E (1995) Evaluation of zinc sources for the newly weaned pig. J Anim Sci 73, Suppl. 1, 72 .

6. Han YK \& Thacker PA (2009) Performance, nutrient digestibility and nutrient balance in weaned pigs fed diets supplemented with antibiotics or zinc oxide. J Anim Vet Adv 8, 868-875.

7. Walk CL, Wilcock P \& Magowan E (2015) Evaluation of the effects of pharmacological zinc oxide and phosphorus source on weaned piglet growth performance, plasma minerals and mineral digestibility. Animal 9, 1145-1152.

8. Sales J (2013) Effects of pharmacological concentrations of dietary zinc oxide on growth of post-weaning pigs: a metaanalysis. Biol Trace Elem Res 152, 343.

9. Looft T, Johnson TA, Allen HK, et al. (2012) In-feed antibiotic effects on the swine intestinal microbiome. Proc Natl Acad Sci U S A 109, 1691-1696.

10. Zanello G, Meurens F, Berri M, et al. (2009) Saccharomyces boulardii effects on gastrointestinal diseases. Curr Issues Mol Biol 11, 47.

11. Zanello G, Berri M, Dupont J, et al. (2011) Saccharomyces cerevisiae modulates immune gene expressions and inhibits ETEC-mediated ERK1/2 and p38 signaling pathways in intestinal epithelial cells. PLOS ONE 6, e18573.

12. Zanello G, Meurens F, Berri M, et al. (2011) Saccharomyces cerevisiae decreases inflammatory responses induced by $\mathrm{F} 4+$ enterotoxigenic Escherichia coli in porcine intestinal epithelial cells. Vet Immunol Immunop 141, 133-138.

13. Badia R, Lizardo R, Martinez P, et al. (2012) The influence of dietary locust bean gum and live yeast on some digestive immunological parameters of piglets experimentally challenged with. J Anim Sci 90, 260-262.

14. Jurgens MH, Rikabi RA \& Zimmerman DR (1997) The effect of dietary active dry yeast supplement on performance of sows during gestation-lactation and their pigs. J Anim Sci 75, 593-597.

15. Trckova M, Faldyna M, Alexa P, et al. (2014) The effects of live yeast Saccharomyces cerevisiae on postweaning diarrhea, immune response, and growth performance in weaned piglets. J Anim Sci 92, 767 .
16. Trevisi P, Colombo M, Priori D, et al. (2015) Comparison of three patterns of feed supplementation with live yeast on postweaning diarrhea, health status, and blood metabolic profile of susceptible weaning pigs orally challenged with F4ac. J Anim Sci 93, 2225-2233.

17. Hou Y, Wang L, Ding B, et al. (2010) Dietary $\alpha$-ketoglutarate supplementation ameliorates intestinal injury in lipopolysaccharide-challenged piglets. Amino Acids 39, 555-564.

18. Hu L, Liu Y, Yan C, et al. (2015) Postnatal nutritional restriction affects growth and immune function of piglets with intrauterine growth restriction. BrJ Nutr 114, 53-62.

19. Shen X, Yi D, Ni X, et al. (2014) Effects of Lactobacillus plantarum on production performance, immune characteristics, antioxidant status, and intestinal microflora of bursinimmunized broilers. Can J Microbiol 60, 193-203.

20. Behrens RH, Docherty H, Elia M, et al. (1984) A simple enzymatic method for the assay of urinary lactulose. Clin Chim Acta 137, 361-367.

21. Blood J, Ingle AR, Allison N, et al. (1991) Rapid enzymatic method for the measurement of mannitol in urine. Ann Clin Biochem 28, 401.

22. Zhang BK \& Guo YM (2009) Supplemental zinc reduced intestinal permeability by enhancing occludin and zonula occludens protein-1 (ZO-1) expression in weaning piglets. Br J Nutr 102, 687.

23. Livak KJ \& Schmittgen TD (2001) Analysis of relative gene expression data using real-time quantitative PCR and the 2 (-Delta Delta C(T)) method. Methods 25, 402-408.

24. Guo Y (2009) Supplemental zinc reduced intestinal permeability by enhancing occludin and zonula occludens protein-1 (ZO-1) expression in weaning piglets. Br J Nutr 102, 687.

25. Giannenas I, Papadopoulos E, Tsalie E, et al. (2012) Assessment of dietary supplementation with probiotics on performance, intestinal morphology and microflora of chickens infected with Eimeria tenella. Vet Parasitol 188, 31-40.

26. Bosi P, Merialdi G, Scandurra S, et al. (2011) Feed supplemented with 3 different antibiotics improved food intake and decreased the activation of the humoral immune response in healthy weaned pigs but had differing effects on intestinal microbiota. J Anim Sci 89, 4043-4053.

27. Yin JD, Li XL, Li D, et al. (2009) Dietary supplementation with zinc oxide stimulates ghrelin secretion from the stomach of young pigs. J Nutr Biochem 20, 783-790.

28. Duan D, Zhang S, Li X, et al. (2014) Activation of the TLR/ MyD88/NF- $\kappa B$ signal pathway contributes to changes in IL-4 and IL-12 production in piglet lymphocytes infected with porcine circovirus type 2 in vitro. PLOS ONE 9, e97653.

29. Kawai T \& Akira S (2009) The roles of TLRs, RLRs and NLRs in pathogen recognition. Int Immunol 21, 317.

30. Uematsu S \& Akira S (2006) The role of Toll-like receptors in immune disorders. Expert Opin on Biol Ther 6, 203-214.

31. Li H, Zhang L, Chen L, et al. (2016) Lactobacillus acidophilusalleviates the inflammatory response to enterotoxigenic Escherichia coli $\mathrm{K} 88$ via inhibition of the NF- $\mathrm{KB}$ and p38 mitogen-activated protein kinase signaling pathways in piglets. BMC Microbiol 16, 273.

32. Trevisi P, Casini L, Coloretti F, et al. (2011) Dietary addition of Lactobacillus rbamnosus GG impairs the health of Escherichia coli F4-challenged piglets. Animal 5, 1354-1360.

33. Jensen ML, Thymann T, Cilieborg MS, et al. (2014) Antibiotics modulate intestinal immunity and prevent necrotizing enterocolitis in preterm neonatal piglets. Am J Physiol Gastrointest Liver Physiol 306, 59-71.

34. Hu CH, Song ZH, Xiao K, et al. (2014) Zinc oxide influences intestinal integrity, the expressions of genes associated with inflammation and TLR4-myeloid differentiation factor 
88 signaling pathways in weanling pigs. Innate Immun $\mathbf{2 0}$ 478-486

35. Roselli M, Finamore A, Garaguso I, et al. (2003) Zinc oxide protects cultured enterocytes from the damage induced by Escherichia coli. J Nutr 133, 4077-4082.

36. Zapater P, González-Navajas JM, Such J, et al. (2015) Immunomodulating effects of antibiotics used in the prophylaxis of bacterial infections in advanced cirrhosis. World J Gastroenterol 21, 11493-11501.

37. Broadway PR, Carroll JA \& Sanchez NCB (2015) Live yeast and yeast cell wall supplements enhance immune function and performance in food-producing livestock: a review[J]. Microorganisms 3, 417-427.

38. Ansanay V, Dequin S, Camarasa C, et al. (1996) Malolactic fermentation by engineered Saccharomyces cerevisiae as compared with engineered Schizosaccharomyces pombe. Yeast 12, 215-225.
39. Ulluwishewa D, Anderson RC, Mcnabb WC, et al. (2011) Regulation of tight junction permeability by intestinal bacteria and dietary components. J Nutr 141, 769

40. Bischoff SC, Barbara G, Buurman W, et al. (2014) Intestinal permeability - a new target for disease prevention and therapy. BMC Gastroenterol 14, 189

41. Michielan A \& D'Incà R (2015) Intestinal permeability in inflammatory bowel disease: pathogenesis, clinical evaluation, and therapy of leaky gut. Mediators Inflamm 2015, 628157.

42. Bontempo V, Giancamillo AD, Savoini G, et al. (2006) Live yeast dietary supplementation acts upon intestinal morpho-functional aspects and growth in weanling piglets. Anim Feed Sci Tech 129, 224-236.

43. Sivignon A, De VA, Barnich N, et al. (2015) Saccharomyces cerevisiae CNCM I-3856 prevents colitis induced by AIEC bacteria in the transgenic mouse model mimicking Crohn's disease. Inflamm Bowel Dis 21, 276. 